\title{
Penyuluhan Kewirausahaan Bagi Kelompok Umkm Guna Meningkatkan Motivasi Dalam Berwirausaha
}

\author{
Netri Rahma Yuliani \\ Fakultas Ilmu Pendidikan, Universitas Negeri Padang \\ email: netrirahma@gmail.com
}

\begin{abstract}
In the village of Tarandam Nagari Siguntur Tua, there is a group of MSME. The community prefers to go to the garden to make a living for the family rather than participate in an activity that is not or less profitable and does not get money in return. Even though if the activities of MSME run optimally, the community can make it as a place for entrepreneurship by utilizing available natural resources, so as to improve the family's economy. Entrepreneurship is an additional alternative part of the activities of MSME so that it is more useful and has added value to families and communities in the Old Siguntur Old Age. So, it is necessary to provide motivation and foster entrepreneurial spirit to the MSME group in Old Agate Siguntur. Therefore, the writer as a student of Field Work Lectures from the Department of Education outside the School of Education at the State University of Padang is interested in discussing and providing alternative solutions to overcome these problems. This is applied to the community service with Entrepreneurship Counseling for MSME To Increase Motivation in Entrepreneurship in Tarandam Nagari Siguntur Tua Village, Tarusan District, South Coastal Province, West Sumatra Province.
\end{abstract}

Keywords : Entrepreneurship Counseling, MSME, Motivation.

\begin{abstract}
Abstrak
Di kampung Tarandam Nagari Siguntur Tua, terdapat kelompok UMK). Masyarakat lebih memilih untuk pergi ke kebun mencari nafkah untuk keluarga dari pada ikut dalam suatu kegiatan yang tidak atau kurang menguntungkan dan tidak mendapatkan uang sebagai imbalannya. Padahal apabila kegiatan UMKM ini berjalan dengan maksimal, masyarakat bisa menjadikannya sebagai wadah untuk berwirausaha dengan memanfaatkan sumber daya alam yang tersedia, sehingga dapat meningkatkan ekonomi keluarganya. Kewirausahaan merupakan bagian alternatif tambahan bagi kegiatan UMKM, sehingga lebih bermanfaat dan mempunyai nilai tambah bagi keluarga dan masyarakat di Kenagarian Siguntur Tua. Maka, perlu memberikan motivasi dan menumbuhkan jiwa kewirausahaan kepada kelompok UMKM di Kenagarian Siguntur Tua. Oleh karena itu, penulis sebagai mahasiswa Kuliah kerja Lapangan (KKL) dari Jurusan Pendidikan Luar Sekolah Fakultas Ilmu Pendidikan Universitas Negeri Padang tertarik untuk membahas dan memberikan alternatif solusi untuk menanggulangi permasalahan tersebut. Hal ini diaplikasikan pada pengabdian kepada masyarakat dengan Penyuluhan Kewirausahaan Bagi Kelompok UMKM Guna Meningkatkan Motivasi dalam Berwirausaha di Kampung Tarandam Nagari Siguntur Tua Kecamatan Tarusan Kabupaten Pesisir Selatan Provinsi Sumatera Barat.
\end{abstract}

Kata kunci: Penyuluhan Kewirausahaan, UMKM, Motivasi

\section{PENDAHULUAN}

Pendidikan merupakan usaha sadar dan terencana untuk mewujudkan suasana belajar dan proses pembelajaran agar peserta didik secara aktif mengembangkan potensinya untuk memiliki kekuatan spiritual, pengendalian diri, kecerdasan, akhlak mulia, serta keterampilan yang diperlukan (UU Sisdiknas No. 20 tahun 2003). Program pendidikan nonformal ada bermacam- macam. Berdasarkan pasal 26 ayat 3 menyebutkan beragam program 
pendidikan nonformal meliputi pendidikan kecakapan hidup, pendidikan anak usia dini, pendidikan kepemudaan, pendidikan keaksaraan, pendidikan keterampilan, pelatihan kerja, pendidikan kesetaraan, serta pendidikan lain yang ditujukan untuk mengembangkan kemampuan peserta didik.

Siguntur Tua merupakan salah satu dari 23 Nagari di Kecamatan Koto XI Tarusan Kabupaten Pesisir Selatan. Kenagarian Siguntur Tua terletak di tepi dialiran sungai Batang Tarusan dan sepanjang bukit barisan. Potensi yang dimiliki daerah ini adalah potensi pertanian dan perkebunan, yang menyebabkan banyak dari masyarakat yang menjadi petani dan buruh. Tanaman andalan di daerah ini yaitu durian dan gambir.

Di kampung Tarandam Nagari Siguntur Tua terdapat kelompok Usaha Mikro Kecil Menengah (UMKM) dimana kelompok tersebut melakukan kegiatan dalam menunjang dalam bidang perekonomian. Dalam perkembangannya kelompok UMKM ini masih terkendala pada pengemasan produk, pemasaran, dan pelaksanaannya. Masyarakat lebih memilih untuk pergi ke kebun mencari nafkah untuk keluarga dari pada ikut dalam suatu kegiatan yang tidak atau kurang menguntungkan dan tidak mendapatkan uang sebagai imbalannya. Padahal apabila kegiatan UMKM ini berjalan dengan maksimal, masyarakat bisa menjadikannya sebagai wadah untuk berwirausaha dengan memanfaatkan sumber daya alam yang tersedia, sehingga dapat meningkatkan ekonomi keluarganya.

Kewirausahaan merupakan bagian alternatif tambahan bagi kegiatan UMKM tersebut sehingga lebih bermanfaat dan mempunyai nilai tambah bagi keluarga dan masyarakat di Kenagarian Siguntur Tua. Oleh karena itu, perlu memberikan motivasi dan menumbuhkan jiwa kewirausahaan kepada kelompok UMKM di Kenagarian Siguntur Tua.

Berdasarkan permasalahan tersebut diperlukan adanya gebrakan untuk memberikan penyadaran dan membuka pola pikir serta cakrawala masyarakat di Kenagarian Siguntur Tua. Salah satu gebrakan yang dapat dilakukan dalam meningkatkan kesadaran masyarakat adalah melalui penyuluhan. Oleh karena itu, penulis sebagai mahasiswa Kuliah kerja Lapangan (KKL) dari Jurusan Pendidikan Luar Sekolah Fakultas Ilmu Pendidikan Universitas Negeri Padang tertarik untuk membahas dan memberikan alternatif solusi untuk menanggulangi permasalahan tersebut. Yaitu dengan membuat sebuah program berjudul "Penyuluhan Kewirausahaan Bagi Kelompok Usaha Mikro Kecil Menengah (UMKM) di Kampung Tarandam, Nagari Siguntur Tua, Kecamatan Tarusan, Kabupaten Pesisir Selatan".

\section{METODE PENGABDIAN}

Metode yang digunakan dalam pelaksanaan pengabdian adalah metode penyuluhan dengan beberapa materi, yaitu motivasi dalam berwirausaha, perencanaan usaha hingga pengemasan dan pelabelan, beserta strategi pemasaran produk, diakhiri dengan diskusi dan tanya jawab antara peserta dengan pemateri

Penyuluhan ini dilaksanakan di rumah ketua kelompok UMKM, tepatnya di Kenagarian Siguntur Tua, Kecamatan Tarusan, Kabupaten Pesisir Selatan. Penyuluhan ini dilaksanakan pada hari Sabtu, tanggal 23 November 2019.

Objek pengabdian ini adalah pelaku UMKM yang berada di Kenagarian Siguntur Tua, Kecamatan Tarusan, Kabupaten Pesisir Selatan, Sumatera Barat. Pelaku UMKM merupakan satu subjek dari Peraturan Pemerintah Nomor 23 tahun 2018, selama UMKM tersebut masih memiliki omset yang tidak melebihi Rp4,8 miliar per tahun.

\section{HASIL DAN PEMBAHASAN}

Kegiatan pengabdian kepada masyarakat ini memberikan materi tentang motivasi dalam berwirausaha, perencanaan usaha hingga pentingnya pengemasan dan 
pelabelan pada produk yang akan di pasarkan, strategi pemasaran produk, serta diberikannya contoh-contoh dari kemasan produk yang lebih menarik pada peserta penyuluhan. Pemateri dalam penyuluhan ini yaitu Achmad Rifaldo dari Mahasiswa Jurusan Manajemen Pemasaran Fakultas Ekonomi Universitas Negeri Padang. Pelaksanaan pengabdian ini dilakukan dalam bentuk penyuluhan, diskusi, tanya jawab, dan penyelesaian kasus yang dialami oleh peserta. Penyuluhan ini diharapkan memberikan manfaat serta bekal pada peserta dalam melanjutkan usahanya, dan dapat memasarkan produknya ke tingkat yang lebih luas lagi dan dikenal banyak masyarakat luas.

Untuk mengetahui pencapaian tujuan dalam kegiatan penyuluhan ini dilakukannya evaluasi. Metode evaluasi yang dilakukan adalah dengan mengamati dari awal dimulainya penyuluhan hingga akhir dilaksanakannya penyuluhan, dimana terlihat peserta yang sangat antusias dan berdiskusi aktif untuk mengetahui dan memahami dari materi-materi yang dipaparkan oleh pemateri. Diharapkan agar kegiatan ini dapat berlanjut dilaksanakan, karena masyarakat sangat merasa terbantu dari segi pengetahuan baru yang didapatkannya. Pemateri dan tim Mahasiswa KKL jurusan Pendidikan Luar Sekolah Universitas Negeri Padang akan siap membantu peserta pelatihan dalam mengembangkan usahanya.

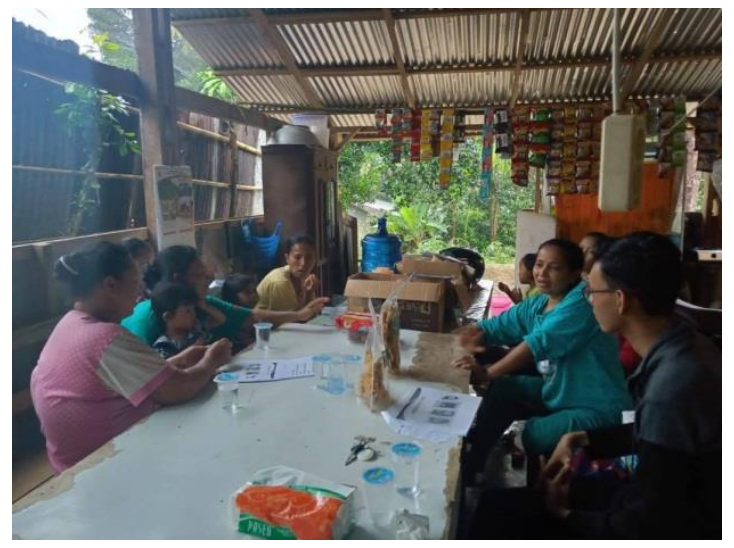

Gambar 1. Kegiatan Penyuluhan

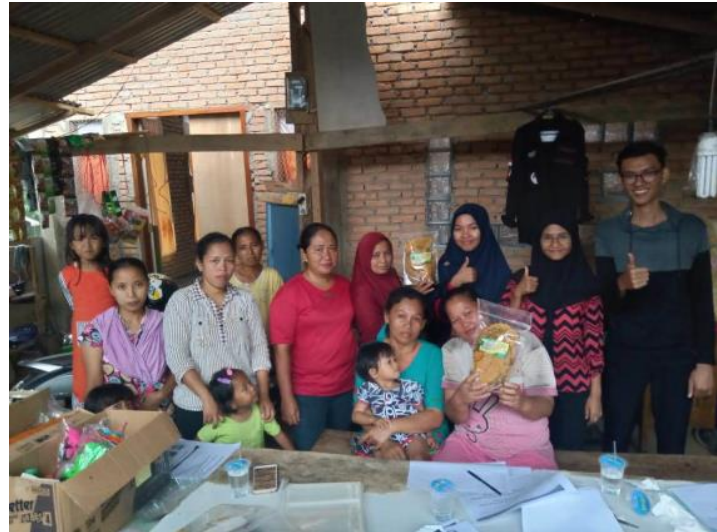

Gambar 2. Penutupan Penyuluhan di Kenagarian Siguntur Tua, 2019.

\section{SIMPULAN}

Berdasarkan hasil pelaksanaan kegiatan pengabdian kepada masyarakat dalam bentuk penyuluhan ini dan uraian pembahasan di atas, dapat disimpulkan beberap hal sebagai berikkut ini.

Penyuluhan ini memberikan beberapa materi yang terkait dengan motivasi dalam berwirausaha, perencanaan usaha hingga pengemasan dan pelabelan, beserta strategi pemasaran produk. Materi yang dipaparkan dapat diterima, dicerna, dan dipahami peserta penyuluhan dengan baik.

Kegiatan berjalan dengan lancar, tepat waktu dan sesuai dengan yang diharapkan. Para peserta penyuluhan dapat berkomunikasi dengan pembicara dan peserta lainnya dengan baik, sehingga sasaran sudah memiliki rencana dalam pengembangan usaha yang dikelolanya.

\section{UCAPAN TERIMA KASIH}

Pengabdi mengucapkan terima kasih kepada Bapak Wali Nagari Siguntur Tua dan pelaku UMKM di Kenagarian Siguntur Tua, Kecamatan Tarusan, Kabupaten Pesisir Selatan yang telah memberikan izin dan berpartisipasi dalam kegiatan pengabdian ini. Pengabdi juga berterimakasih kepada dosen pembimbing yang telah memberikan bimbingannya dalam pelaksanaan program ini, serta kepada pemateri yang sudah membantu pengabdi dalam memberikan ilmu 
pengetahuannya kepada peserta dalam pengabdian ini.

\section{DAFTAR PUSTAKA}

[1] Almar, Buchori. 2001. Kewirausahaan. Bandung : Alfabeta.

[2] Mardikanto, T. 1993. Penyuluhan Pembangunan Pertanian. Surakarta : UNS Press.

[3] Prasetyo, Aziz Turindra. 2010. Tingkat Partisipasi Masyarakat Desa Miskin Dalam Kegiatan Simpan Pinjam Khusus untuk Perempuan di Kecamatan Bendosari Kabupaten Sukoharjo. Surakarta : UNS Press.

[4] S. Negara, " Peraturan Pemerintah Nomor 23 Tahun 2018 Tentang Pajak Penghasilan Atas Penghasilan dari Usaha yang Diterima atau Diperoleh Wajib Pajak yang Memiliki Peredaran Bruto Tertentu.,"2018.

[5] IS. Negara, "UU Sisdiknas No. 20 tahun 2003 tentang Sistem Pendidikan Nasional.," 2003. 